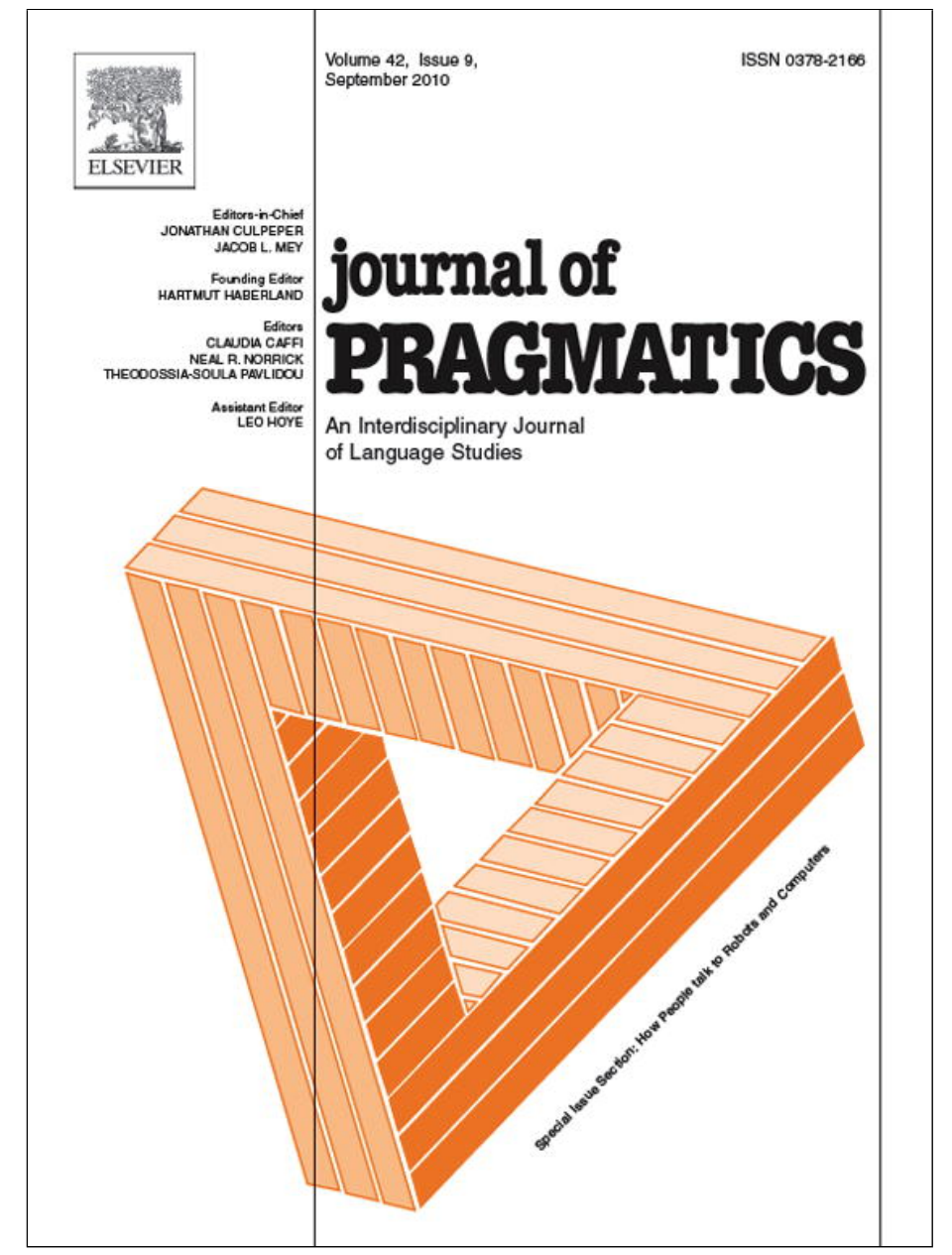

This article appeared in a journal published by Elsevier. The attached copy is furnished to the author for internal non-commercial research and education use, including for instruction at the authors institution and sharing with colleagues.

Other uses, including reproduction and distribution, or selling or licensing copies, or posting to personal, institutional or third party websites are prohibited.

In most cases authors are permitted to post their version of the article (e.g. in Word or Tex form) to their personal website or institutional repository. Authors requiring further information regarding Elsevier's archiving and manuscript policies are encouraged to visit:

http://www.elsevier.com/copyright 


\title{
The discourse function of inverse voice: An experimental study in Teribe (Chibchan)
}

\author{
J. Diego Quesada ${ }^{a}$, Stavros Skopeteas ${ }^{\mathrm{b}, *}$

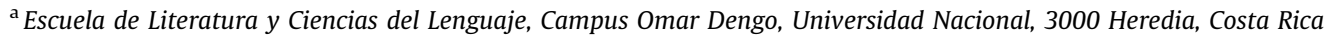 \\ ${ }^{\mathrm{b}}$ SFB 632 Institut für Linguistik . Universität Potsdam, Karl-Liebknecht-Str. 24/25 14476 Potsdam (Haus 24, Zimmer 266), Germany
}

\section{A R T I C L E I N F O}

\section{Article history:}

Received 11 February 2008

Received in revised form 24 September 2009

Accepted 7 February 2010

\section{Keywords:}

Teribe

Inverse voice

Topic

Focus

Production experiment

\begin{abstract}
A B S T R A C T
It has been argued that the use of inverse voice in languages with pragmatic inversion depends on the discourse status of the referents: this voice occurs when the patient outranks the agent in topicality. In our article, we present empirical evidence from Teribe, a Chibchan language of Panama and Costa Rica and we examine the interaction between inverse voice and information structure. We report the results of three production experiments which show that there is a strong correlation but not a categorical association between inverse voice and particular information structural properties. On this empirical basis, we claim that the occurrence of inverse voice in discourse may be accounted for in terms of discourse-oriented preferences concerning the linear order and does not require the assumption that discrete pragmatic properties such as topic or focus are inherent part of the construction at issue.
\end{abstract}

(c) 2010 Elsevier B.V. All rights reserved.

\section{Introduction}

It is a common tenet of modern linguistics of different frameworks that the choice among alternative morpho-syntactic structures that encode the same propositional content is determined by pragmatic or discourse functions. A wide array of constructions such as voice distinctions, dislocations to the left or to the right of the clause boundaries, as well morphological markers such as topic particles are often regarded as manifestations of particular information structural concepts. In this vein, passive has been regarded as an agent-defocusing strategy across languages (Shibatani, 1985:837), word order alternations have been accounted for as triggered by the existence of functional clausal positions for topic and focus (Rizzi, 1997; Kiss, 1998), cleft constructions in French and English have been analyzed as means to partition the conveyed propositional content into presupposed and focused information (Lambrecht, 2001), and so on. However, it has been shown in several cases that the assumed form-function associations are often not categorical, i.e., that the identified functions are not a necessary and sufficient condition for the occurrence of the corresponding form. A paradigm of recent accounts points out that the form-function associations of this kind are the epiphenomenal result of rather abstract properties of grammatical constructions, such as the existence of more and less prominent positions in the linear order or the interaction between syntactic structure and preferences in the prosodic realization of the utterance (see for instance Szendroi, 2001; Fanselow, 2006, 2007; Féry, 2006; Wedgwood, 2003).

This article deals with the discourse functions of inverse voice. Previous literature distinguishes between semantic and pragmatic inversion (see Givón, 1994a,b:23). The former is determined by inherent properties of the participants

\footnotetext{
* Corresponding author. Tel.: +49 331977 2968; fax: +49 3319772925.

E-mail addresses: jquesad@una.ac.cr (J.D. Quesada), skopetea@rz.uni-potsdam.de (S. Skopeteas).
} 
(e.g., animacy), while the latter depends on the discourse status of the arguments. In our article, we deal with pragmatic inversion and we address the question of how the structural contrast between direct and inverse voice interacts with information structure. Crucially, in a part of the previous literature an isomorphism between the different kinds of voice alternation and information structural properties has been suggested (Cooreman, 1987; Givón, 1994a,b). The basic observation is that inverse voice differs from passive voice in that it involves a symmetrical exchange of the status of the arguments. Isomorphism between form and function implies that the syntactic symmetry reflects a functional symmetry. In particular, the agent constituent in inverse voice retains an information state which is identical to the information state of patients in active voice, while the agent constituent in passive voice has an information state which is more marginal than the information state of patients in active voice (the exact nature of information states is defined differently depending on account; it relates, for instance, to the topicality scale in Givón, 1994a,b or to the prominence scale in Aissen, 1999a:687; see detailed discussion in section 2.2).

Teribe, a Chibchan language of Panama and Costa Rica, exhibits a construction that fits the pattern of pragmatic inversion. Direct and inverse voice are exemplified in (1a)-(1b), respectively (see detailed discussion in section 3.2). Following differences may be observed in these examples: (a) different affixes are attached to the verb, (b) word order is SOV in direct voice and OVS in inverse, (c) the agent constituent is accompanied with a morphological marker dë 'oBv' in the inverse voice.

\section{(a) Carlos Jacinto shpo-no. \\ Carlos Jacinto hit-PFV \\ 'Carlos hit Jacinto.'}

(b) Jacinto shpo-ra Carlos dë.
Jacinto hit-PFV.INV Carlos OBV
'Carlos hit Jacinto.'

Aim of this article is to account for the discourse functions of inverse voice in Teribe. Section 2 introduces the concept of inverse voice and section 3 the relevant constructions of Teribe. The following chapters constitute the main body of our empirical study, which is based on production experiments. The first experiment shows that inversion in Teribe is sensitive to givenness asymmetries (see section 4). The second experiment shows that inversion is sensitive to narrow focus (see section 5). Section 6 takes a closer look to some single examples and shows that an underspecified concept of 'discourse prominence' accounts for the obtained data better than discrete information structural concepts such as topic or focus. Discourse prominence is a relational concept between the clausal arguments and relates to a particular discourse span, as shown in section 7. In the concluding section, we argue that the structural possibility of voice inversion creates two alternative linearization options. The choice of voice is influenced by pragmatic principles that apply on the linearization, but there is no reason to assume that the two voices are unambiguously associated with particular discourse functions.

\section{Theoretical background}

This section presents a structural definition of the phenomenon of voice inversion (section 2.1), outlines the most important accounts of the pragmatics of this construction (section 2.2), and introduces the basic information structural concepts which we are using in this article (section 2.3).

\subsection{Structural properties of inverse voice}

Inversion refers to a 'direct vs. inverse' voice alternation that does not affect the transitivity of the verb. ${ }^{1}$ While passivization derives an intransitive verb on the basis of a transitive one, in inversion both input and output of the syntactic derivation are transitive (see Klaiman, 1991:183; Dixon and Aikhenvald, 1997:100). ${ }^{2}$ Moreover, inversion does not necessarily involve a change in the syntactic status of the arguments, i.e., if there is evidence for an argument asymmetry in the language at issue, this asymmetry applies uniformingly in direct and inverse clauses, at least in a subset of languages with inverse systems. For this reason, the concept of argument status which is used to describe the choice of voice in an inverse system is independent of the syntactic function of the arguments. A separate tier of hierarchically organized statuses is used for this purpose, i.e., the 'obviation tier' (see Aissen, 1997). Two obviation states have to be distinguished in this tier: (a) the 'proximate status' which is the highest argument in the obviation ranking, and (b) the 'obviative status' which characterizes the non-highest argument(s). The distinction between proximate and obviative only applies to third person nominals.

The choice of voice in inverse systems depends on the interaction of the obviation status with the hierarchy of $\boldsymbol{\theta}$-roles (agent > patient; cf. Silverstein, 1976; Dik, 1980; Lehmann et al., 2002). Two basic configurations are distinguished: in the unmarked configuration (direct voice), the $\boldsymbol{\theta}$-role hierarchy is harmonically aligned with the obviation hierarchy, i.e., the highest $\boldsymbol{\theta}$-role is aligned with the highest obviation status; in the marked configuration (inverse voice), the alignment

\footnotetext{
${ }^{1}$ An alternative term for the superordinate concept is “direction” (see Aissen, 1997; Zúñiga, 2006).

2 The reader must be aware that there are different and partly controversial definitions of inversion in the literature (see Zúniga, 2006:29-46 for an overview).
} 
between these hierarchies is disharmonic, i.e., the highest $\theta$-role is aligned with the lower obviation status, as schematically illustrated in (2) (partially adopted from Aissen, 1999a:460). Hence, the change of argument status is completely symmetrical, i.e., the actor of the direct voice has the same status with the undergoer of the inverse voice and vice versa.

(2) (a) direct voice

$\begin{array}{lcl}\theta \text {-role: } & \text { agent } & >\text { patient } \\ \text { obviation status: } & \text { proximate }>\text { obviative }\end{array}$

(b) inverse voice:

o-role:

The exact factors that determine the choice between direct and inverse voice differ across languages. Several hierarchies such as the locality of person (local first and second persons vs. non-local third person), ontological status (animate vs. inanimate), syntactic relations such as possessor vs. possessed NP, and pragmatic relations (such as topical vs. non-topical) may interact for the choice among direct and inverse voice (see Givón, 1994a,b; Aissen, 1997; Zúñiga, 2006).

\subsection{Pragmatic properties of inverse voice}

A number of empirical studies on the pragmatics of inversion have arisen within the framework of Givón (1994a,b). Following Cooreman (1987) and Givón (1994a,b), the voice system in these languages is aligned with the pragmatic dimension of "relative topicality". The concept of "topicality" in this framework is specified as "thematic importance" and has little to do with the notion of sentential topic. It rather relates to a concept of 'discourse topic', regarded as a scalar notion that combines the pragmatic properties of the argument in two dimensions: the prominence of a referent within the array of referents that are available in the previous discourse and the prominence of the referent within the array of referents that are planned to occur in the subsequent discourse (in the mental model of the speaker at the time of the utterance). This concept is empirically assessed by two measures: (a) the measure of referential distance (anaphoric measure) which captures the distance (counted in sentences) of the argument at issue to the last occurrence of a co-referent NP in the preceding text, and (b) the measure of topic persistence (cataphoric measure) which captures the occurrences of this referent in the subsequent text (see Givón, 1994a,b:10ff.). A low score in the anaphoric dimension, which means that the referent is available in the immediate preceding text, or a high score in the cataphoric dimension, which means that the referent is continuously mentioned in the subsequent text, result in a high score in relative topicality. Following the rationale of these measurements, the identified pragmatic properties of syntactic constructions are probabilistic relations between syntactic and pragmatic configurations and not form-to-function associations in terms of necessary and sufficient conditions.

Based on these heuristics for the measurement of relative topicality, the crucial claim within this framework is that there is an isomorphism between syntactic and pragmatic properties. Passivization is an asymmetric change of the argument status of the involved participants. Iconically, the discourse properties of passives involve a large asymmetry between agent and patient in relative topicality. In inverse voice, on the other hand, the participants symmetrically exchange their argument status, which is reflected in their pragmatic properties: the agent in inverse voice has the same pragmatic properties as the patient in direct voice and vice versa. These predictions are summarized in (3).

(3) voice relative topicality

active/direct AGT $>$ PAT

inverse $\quad$ PAT $<$ AGT

passive $\quad$ PAT $\ll$ AGT

The predictions made in (3) are born out in corpus studies in several languages (see Givón, Ed., 1994). However, the correlations to textual mentions do not account for the clause-level pragmatic functions that may influence the choice of syntactic construction. Furthermore, the measurement of textual mentions alone lets aside a significant subset of the information which is part of the common ground of the speaker and the hearer without having an antecedent in the discourse ${ }^{3}$ : (a) situationally evoked referents; (b) referents that may be inferred from already given referents in discourse; (c) referents that are part of the shared cultural knowledge (see Chafe, 1994; Gundel et al., 1993; Lambrecht, 1994; Prince, 1981).

\footnotetext{
${ }^{3}$ This point is already made by Thompson (1994:50) who shows that measurements taking into account other sources for referent accessibility replicate the results of text based measurements.
} 
Apart from "topicality", which is a recurrent concept in studies on inversion, several accounts refer to the role of "discourse prominence" as a basis for reference tracking (see Whistler, 1985; Aissen, 1997, 1999b). Establishing (co-) referential relations in discourse is a major function of these voice systems, especially when more than one-third person referents are available in the context. Cross-linguistically it has been observed that inversion predominantly occurs in languages in which alternative means for encoding co-reference, for instance overt pronouns, are sparse (see Aissen, 1999a). Discourse prominence accounts assume that at any point in discourse, an array of referents is available that are hierarchically ranked with respect to their degree of activation. The choice among direct and inverse voice refers to this ranking. The most "prominent" participant reserves the proximate status, determining thus the choice of direct or inverse voice.

In all accounts mentioned above, the choice among direct and inverse voice is related to the broader textual context without mentioning the relevance of information structural properties at the sentence level. A number of studies show that sentence level pragmatic concepts such as topic and focus have a direct impact on the choice of voice in an inverse system (see Jelinek, 1990; Jelinek and Willie, 1996, as well as Aissen, 2000, on Navajo). Relevant questions at this level are: What is the role of sentential topics in the choice of voice? Is inversion influenced by sentence focus? Our account will concentrate on questions at that level.

\subsection{Basic concepts of information structure}

In order to account for our data, we will introduce some central concepts of information structure. Following standard assumptions in the literature, we will adopt three fundamental dimensions of discourse properties:

Discourse status of the referents. The distinction between "new" and "given" information relates to the availability of a part of the utterance in the explicit common ground. A further concept of "accessible" information is used whenever we wish to refer to information which is assumed to be part of the common ground without being yet introduced in discourse, e.g., situationally available, culturally presupposed or inferred information (see Chafe, 1994; Gundel et al., 1993; Krifka, 2007; Lambrecht, 1994; Prince, 1981).

Topic-comment articulation. We follow Reinhart (1982) in assuming that the topic of a sentence is what the sentence is about. Topics are not necessarily given information (though they often are); the only requirement is that a pragmatic relation of aboutness holds between the topic and the rest of the sentence, i.e., the comment.

Focus-background articulation. The focused part of the utterance is the asserted information; the part which is out of focus, i.e., the background, contains the presupposed information. Several subtypes of focus have to be distinguished: 'new information focus' introduces new referents in discourse, 'contrastive focus' asserts that the proposition holds true for the focused referent in contrast to another relevant referent in discourse (see Kiss, 1998).

\section{Teribe and inversion}

This section outlines the necessary grammatical background for the interpretation of the linguistic data presented in the following sections. Section 3.1 outlines the grammatical properties of Teribe that are relevant for our study. Section 3.2 summarizes the syntactic properties of inversion in this language, and section 3.3 introduces some related constructions that are sensitive to information structure.

\subsection{Preliminaries about Teribe}

Teribe is a Chibchan language currently spoken by a population of approximately 1000 people in Northwestern Panama and in the South Pacific region of Costa Rica. The grammar of the language is characterized by a sparse morphological system (see details in Quesada, 2000). Nominal inflection is practically limited to a number distinction (singular/plural) (see (4a)). Nouns are accompanied by numeral classifiers which exhibit a distinction of six noun classes (see (4b)). Adpositions follow the NP (see (4c)).
(a) walë walë-ga
woman woman-PL
'woman' 'women'
$\begin{array}{lll}\text { (b) wale } & k l \text {-ara } \\ \text { woman } & \text { CL.ANIM-one }\end{array}$
'one woman'
(c) sbi dorko
pot under
'under the pot'
sbi kw-ara
pot CL.ROUND-one
'one pot'
sbi shko
pot in
'in the pot' 
Table 1

Personal pronouns and person affixes.

\begin{tabular}{lll}
\hline & Free pronouns & Oblique \\
\cline { 2 - 3 } & Nominal & bor \\
\hline 1.SG & ta & bop \\
2.SG & pa & ba \\
3.SG & $\varnothing$ & borwa \\
1.PL (exclusive) & tawa & bi \\
1.PL (inclusive) & shi & bomi \\
2.PL & pãy & ba \\
3.PL (same subject) & $\varnothing$ & ba \\
3.PL (different subject) & ebga & - -rwa \\
\hline
\end{tabular}

Verbal inflection includes four categories: (a) aspect (see (5a)), that involves perfective, perfect, sudden, imperfective, prospective, and progressive (see Quesada, 2000:71-76); (b) mood/modality (see (5b)), that involves imperative, abilitative, and deontic (see Quesada, 2000:79-82); (c) inversion, which is dealt with in detail in section 3.2; (d) person marking under particular syntactic conditions (see Table 1 ).
(a) pa parko-gdo
pa parko-no
2.SG work-PRF 2.SG work-PFV
'you have worked' 'you worked'
(b) pa shpo-r
2.SG hit-1.SG
'I hit you'
pa shpo-r-ga
2.SG hit-1.SG-ABIL
'I can hit you'

Personal pronouns fall into two paradigms, called "nominal" and “oblique" (see Quesada, 2000:45f. for further discussion), that are listed in Table 1 (the difference between these paradigms is discussed in section 3.2). In a particular syntactic configuration, person is encoded through the affixes that are presented in the last row of Table 1 (see discussion in section 3.2). The alternation between different person markers in the third person is determined by verb class (see Quesada, 2000:84).

\subsection{Word order and inversion}

The most frequent configuration in which transitive clauses appear in spontaneous discourse involves a pronominal subject and a lexical object NP. ${ }^{4}$ These clauses display an OV-s order, where -s stands for a person-indexing suffix from the class of pronominal affixes presented in Table 1 (see illustrative example in (6)). The pronominal subject is neither an agreement nor a cross-reference marker: A lexically realized subject NP excludes the pronominal indexing of the subject and vice versa. In this sense, OV-s is a genuine word order configuration and not an instance of argument ellipsis. ${ }^{5}$ The configuration with pronominal affixes only appears with transitive verbs and it alternates with the SOV configuration involving a free pronominal S. The OV-s option occurs in contexts in which the subject is part of the background information of the clause.

(6) Jacinto shpo-ro-r.

Jacinto hit-PFV-1.SG

'I hit Jacinto.'

When both arguments of a transitive verb are lexically realized, then two orders occur, as introduced in (1a-b), repeated here as (7): the SOV order in which the verb appears in direct voice, and the OVS order in which the verb appears in inverse voice and the subject is marked as obviative by the free morpheme dë. Further argument order permutations are excluded as ungrammatical. Inversive morphology is available in the perfective (suffix $-r a$ ) and the imperfective aspect $(-y a \sim$ $-k \sim-g a \sim-n a$ depending on verb class, see Quesada, 2000:148). The further aspects (perfect, sudden, prospective, progressive) do not have morphological markers of inversion, but the contrast between the SOV and OVS(dë) options appears in any aspect.

\footnotetext{
${ }^{4}$ The tendency to avoid clauses with more than one lexically realized argument as well as the fact that sentences with subject pronouns are more frequent than sentences with object pronouns are in accordance with universal preferences for the preferred argument structure in discourse, as it is shown by Du Bois (1987 and subsequent work).

${ }^{5}$ Clauses with pronominal objects are possible in Teribe, see examples (9b-d) below. Object pronouns are never realized postverbally and are never realized as affixes.
} 
(7) (a) Carlos Jacinto shpo-no.

Carlos Jacinto hit-PFV

'Carlos hit Jacinto.'

(b) Jacinto shpo-ra Carlos dë.

Jacinto hit-PFV.INV Carlos OBV

'Carlos hit Jacinto.'

Postpositional constituents are placed postverbally as exemplified in (8a) with a locative phrase and in (8b) with a recipient phrase. There is morpho-syntactic evidence that recipients, benefactives, and experiencers have a grammaticalized status in Teribe. They are the only postpositional phrases that can host pronouns of the nominal paradigm when fronted (see examples and discussion in Quesada, 2000:113).

(a) Ta be-no sök u shko.

1.SG remain-PFV stay house in

'I stayed in the house.' (Quesada, 2000:115)

(b) Bor dbur e two-zong bor kong iröng!

1.SG money DEM give-IMPR 1.SG to again

'My money, give it back to me!' (Quesada, 2000:126)

From the data presented so far, the OVS(dë) configuration may be thought to have the structural properties of a passive. In the marked voice exemplified in (7b), the agent constituent is placed in the postverbal field, which otherwise hosts postpositional constituents and is marked as oblique. Nevertheless, both coding and behavioral properties of this construction clearly show that the postverbal agent in the OVS(dë) configuration retains its subject status.

Coding evidence for grammatical relations comes from the use of pronouns (see forms in Table 1). Pronouns of the nominal paradigm are used for subjects of intransitive (9a) and transitive verbs (9b) as well as objects of transitive verbs when the subject is realized as a suffix (OV-s order, see (5) and Quesada, 2000:108 for further discussion). Pronouns of the oblique paradigm are used for governed constituents, either verb objects (9b-c) or postpositional objects $9 a$ ), but not for subjects. Crucially, in the OVS example in (9d), it is the nominal form that is used and not the oblique one, which would be expected if the obviative marker dë was a postpositional head governing its pronominal complement.
(a) $\mathrm{Ta}$ to bop tok.
1.SG go 2.SG.OBL with
'I go with you.'
(b) $\mathrm{Ta}$ bop kimtë.
1.SG 2.SG.OBL help
'I help you.'

(c) $\mathrm{Pa}$ bor kimtë.

2.SG 1.SG.OBL help

'You help me.'

(d) $B a \quad z r o ̈-g a \quad$ ta dë.

3.SG kill-IPFV.INV 1.SG OBV

'I kill him.'

The behavioral properties of the inverse construction show that there is an argument asymmetry (agent $>$ patient) which holds independently of the direct-inverse alternation. A control test is exemplified in (10): the single argument of the intransitive verb in (10a) and the subject of the direct transitive verb in (10b) are interpreted as subjects of the matrix verb. Strikingly, it is the agent argument in (10c) which backwards controls the subject of the matrix verb and not the patient, which would be the case if the patient were promoted in a higher syntactic function in a passive-like voice.

(a) Juan jëk wo-ydë.

Juan walk want-PROSP

'Juan wants to walk.' 
(b) Juan Maria ik wo-ydë.

Juan Maria see want-PROSP

'Juan wants to see Maria.'

(c) Maria $\tilde{\imath}$-ya Juan dë wo-ydë.

Maria see-IPFV.INV Juan OBV want-PROSP

'Juan wants to see Maria.'

The view that the obviative agent retains the highest syntactic function is furthermore supported from the binding properties of the two constructions. In the direct configuration, it is only the subject argument that may bind the object (11a), and not vice versa (11b).

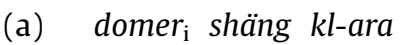
$b a_{\mathrm{i}} \quad$ tlẽklo $\tilde{\imath}$.
man stand CL.ANIM-one 3.SG phone see
'A $\operatorname{man}_{\mathrm{i}}$ sees his phone.'
(b) ${ }^{*} b a_{\mathrm{i}}$ shiti walë shäng kl-ara wuë.
3.SG dog woman stand CL.ANIM-one eat
'Her ${ }_{\mathrm{i}}$ dog bites the woman $_{\mathrm{i}}$ '.

Binding properties of the inverse configuration are shown in (12). In (12a), the object constituent binds its subject postcedent. On the basis of (11a) and (12a), we conclude that antecedents bind their postcedents independently of linear order. The crucial example is (12b) in which the postcedent binds its antecedent. This example may be accounted for, if we assume that binding properties reflect the hierarchy of arguments. In this view, this example provides evidence that the obviative binder fulfills a higher syntactic function than the proximate bindee (note that an English translation of (12b) in passive voice renders an ungrammatical sentence: $h i s_{\mathrm{i}}$ phone is seen by $a \mathrm{man}_{\mathrm{i}}$ ).
(a) walë shäng kl-ara wuë $b a_{\mathrm{i}}$ shiti.
woman stand CL.ANIM-one eat 3.SG dog
'Her ${ }_{\mathrm{i}}$ dog bites the woman ${ }_{\mathrm{i}}$.'
(b) $b a_{\mathrm{i}}$ tlêklo $\tilde{i}$-ya domer $\mathrm{i}_{\mathrm{i}}$ shäng kl-ara dë.
3.SG phone see-IPFV.INV man stand CL.ANIM-one OBV

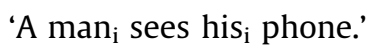

The examples in (13) show that the assumed binding relations hold also for existentially quantified NPs, which excludes that the binding relations observed so far are the result of accidental co-reference (with an assumed antecedent).
(a) bapinga $a_{\mathrm{i}}$ kl-ara
kl-ara
$b a_{\mathrm{i}} \quad$ opinga e wo-ydë.
teacher CL.ANIM-one CL.ANIM-one 3.SG pupil that want-PROSP
'Every teacher likes his $_{\text {i }}$ pupil.'
(b) $\quad b a_{\mathrm{i}}$ opinga $e$ wo-ydë bapinga $a_{\mathrm{i}} k$-ara
3.SG pupil that want-PROSP teacher CL.ANIM-one CL.ANIM-one OBV
'Every teacher likes his $_{\text {i }}$ pupil.'

In concluding, the evidence for syntactic asymmetries between two arguments of transitive verbs suggests that the syntactically highest constituent is always the agent. It is crucial for an account of information structure that inversion in Teribe is obligatorily associated with particular word orders, i.e., the choice of voice is unambiguously associated with the choice of a particular linearization of the arguments (direct $\leftrightarrow$ SOV; inverse $\leftrightarrow$ OVS). This differs from free word order languages like Plains Cree (see Mühlbauer, 2007), in which inversion accounts for the affixation patterns of the arguments independently of word order. In an inverse system that is determined by the word order we expect that pragmatic principles that affect the linearization of conveyed information will have a direct impact on the choice of voice.

\subsection{Related constructions}

Teribe has some further constructions which are sensitive to information structure (see also Quesada, 2000:55-63). Nominals may be accompanied by a topic marker $l i$, which should be understood as a familiarity topic rather than as an aboutness topic. It optionally occurs with nouns denoting introduced referents and is attested in all clausal positions. 
A constituent bearing the marker $l i$ may be focused. A further function of the marker $l i$ is the nominalization of clausal constituents for the formation of relative clauses, as exemplified in (14b).

(a) domer li shäng dibäng bokshto.

man TOP stand well front

'The man is in front of the well.'

(b) k'u buk li je-no.

alligator lie REL disappear-PFV

'The alligator that was there disappeared.'

Left-dislocation occurs very frequently in discourse. Left-dislocated NPs are cross-referenced within the clause by a resumptive pronoun, $e$, as illustrated in (15).

$$
\begin{aligned}
& \text { ëng, domer e p'o-no k'or go. } \\
& \text { yes man that smash-PFV tree with } \\
& \text { 'Yes, the man, he clashed with the tree.' }
\end{aligned}
$$

\section{Ontological vs. discourse status ${ }^{6}$}

Across languages, inversion is reported to be triggered by two independent factors (see Givón, 1994a,b). The first factor is semantic and relates to the ontological status of the entities: inversion is triggered when the argument with the lower $\theta$-role outranks the higher argument in animacy hierarchy. The second factor is pragmatic and relates to the discourse status of the referents: inversion is triggered when the argument with the lower $\boldsymbol{\theta}$-role outranks the higher argument in the givenness hierarchy. Aim of the following experiment is to examine whether these factors have an impact on Teribe inversion.

\subsection{Method}

This experiment aims at the elicitation of short narratives by means of picture descriptions. The informant is shown two pictures and is instructed to describe the presented scenes as if they were parts of a unique story (see exemplification in (16)). The first scene is used to establish the intended context: it presents an entity, either animate or inanimate. After describing the first picture, the informant is shown the second one, which contains the critical situation: it presents an event in which the already introduced entity is involved either as an agent or as a patient. The critical situations contain events that are likely to be lexicalized through transitive verbs across languages (e.g., 'hit', 'kick', 'push', 'carry', 'hold', etc.).

Two factors were implemented in the experimental design: (a) the discourse status of the referents Level $_{1}$ :

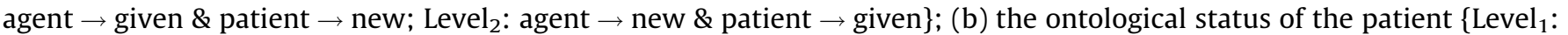
patient $\rightarrow$ animate; Level $_{2}$ : patient $\rightarrow$ inanimate . Crossing the two factors results in four experimental conditions which are presented in (16).

\section{Conditions for Experiment I}

$\mathrm{A}_{\text {giv }} \& \mathrm{P}_{\mathrm{an}}$ : agent animate/given \& patient animate/new

[sc-1]: 'a boy ${ }_{i}$ is standing on the floor'; [sc-2]: 'the boy $y_{i}$ is kicking a man'

$\mathrm{A}_{\text {giv }} \& \mathrm{P}_{\mathrm{in}}$ : agent animate/given \& patient inanimate/new

[sc-1]: 'a boy bo $_{i}$ standing on the floor'; [sc-2]: 'the boy $y_{i}$ is kicking a bottle'

$\mathrm{P}_{\text {giv }} \& \mathrm{P}_{\mathrm{an}}$ : agent animate/new \& patient animate/given

[sc-1]: 'a $\operatorname{man}_{\mathrm{i}}$ is sitting on the floor'; [sc-2]: 'a boy is kicking the $\operatorname{man}_{\mathrm{i}}$ '

$\mathrm{P}_{\text {giv }} \& \mathrm{P}_{\text {in }}$ : agent animate/new \& patient inanimate/given

[sc-1]: 'a bottle $e_{i}$ is standing on the floor'; [sc-2]: 'a boy is kicking the bottle'

The conditions in (16) were implemented in 8 items containing different events, thus rendering a design of 4 (conditions) $\times 8$ (items) $=32$ elements. Each item contained the same target scene in two versions: a version with animate patient and a version with inanimate patient (see stimuli in Skopeteas et al., 2006:39-73). Further asymmetries have not been taken into account in the experimental design, e.g., the age differences between animate referents in the Conditions

\footnotetext{
${ }^{6}$ The presented empirical methods are part of QUIS, which is a collaborative product of the project Typology of Information Structure (part of the SFB 632 on Information Structure, University of Potsdam and Humboldt University Berlin). QUIS is a tool for linguistic fieldwork which contains a set of stimuli-based experimental procedures for the study of information structure. A full documentation of the experiments including stimuli, instructions, and a description of the experimental procedure may be found in Skopeteas et al. (2006).
} 
' $\mathrm{A}_{\text {giv }} \& \mathrm{P}_{\text {an }}$ ' and ' $\mathrm{P}_{\text {giv }} \& \mathrm{P}_{\text {an }}$ ' in (16), since we did not have any hypothesis that such a distinction may have an impact in Teribe. Nevertheless, the same scene was used in both conditions; hence, the effect of the contextual manipulation is independent of the potential effect of the asymmetry between age groups. If a grammar uses inversion when the patient outranks the agent in age, then an amount of inverse clauses is expected to appear in the expressions collected with this item in both conditions with two animates (' $\mathrm{A}_{\text {giv }} \& \mathrm{P}_{\text {an }}$ ' and ' $\mathrm{P}_{\text {giv }} \& \mathrm{P}_{\text {an }}$ ').

The 32 elements were distributed in four field sessions containing tasks from four pseudo-randomized production experiments used as fillers to each other. The distribution in sessions was made on a factorial basis such that each item was presented once in each session and each of the four conditions twice. Four native speakers have performed all four sessions at different appointments, which renders a data set of 4 (speakers) $\times 4$ (sessions) $\times 8$ (descriptions) $=128$ picture descriptions in total. ${ }^{7}$

This experimental design is testing the possible interaction of two factors: (a) discourse status, (b) ontological status. In languages with pragmatic inversion, we expect to obtain a main effect of the former factor, while in languages with semantic inversion we expect to obtain a main effect of the latter factor.

It has been already shown in Quesada (2000:154) that no effects of the ontological saliency hierarchy occur between third person arguments in Teribe. With this background, we predict that inversion will be induced whenever the patient outranks the agent in the givenness hierarchy (given $>$ new), i.e., in the Conditions ' $\mathrm{P}_{\text {giv }} \& \mathrm{P}_{\text {an }}$ ' and ' $\mathrm{P}_{\text {giv }} \& \mathrm{P}_{\text {in }}$ '. If inversion in Teribe were influenced by the ontological status, then inverse constructions should be eliminated in Condition ' $P_{\text {giv }} \& P_{\text {in }}$ ', since the inverted agent would outrank the patient in animacy hierarchy (animate $>$ inanimate). However, according to the previous observations about the function of inversion in this language, this is not the expected result.

\subsection{Results}

Our hypotheses concerning the use of inversion can be tested in the subset of elicited descriptions that fulfill the following requirements: (a) only the referent which is intended to be given is already introduced in the discourse, (b) the target event is lexicalized by a transitive verb. Descriptions that do not meet these requirements were classified as "other". A violation of requirement (a) is presented in (17). This example illustrates a pattern that is common across languages: the new agent is introduced in an intransitive clause (either with a presentational verb like 'appear' or with a motion verb like 'come'), which has the effect that the agent of the transitive clause is not part of the new information.

$$
\begin{aligned}
& \text { [sc-1] dulas shäng zron. [sc-2] domer shäng kl-ara, } \\
& \text { boy stand run man stand CL.ANIM-one } \\
& \text { shäng dula-s sha-no ba orkwo go. } \\
& \text { stand boy take-PFV 3.SG hand with } \\
& \text { '[sc-1] A boy is running. [sc-2] There is a man; he took the boy with his hands.' }
\end{aligned}
$$

In some cases, the stimuli failed to induce a transitive clause in the target descriptions, as illustrated in (18). These descriptions violate requirement (b).

$$
\begin{aligned}
& \text { [sc-1] walë jëk shäng kl-ara. [sc-2] walë jëk } \\
& \text { woman walk stand CL.ANIM-one woman walk } \\
& \text { shäng kl-ara li e kokso no shäng kl-ara. } \\
& \text { stand CL.ANIM-one REL that back person stand CL.ANIM-one } \\
& \text { '[sc-1] A woman is walking. [sc-2] On the back of the woman that is walking, there is a person.' }
\end{aligned}
$$

The rest of the elicited descriptions are valid tokens for the observation of the impact of the experimental factors on the

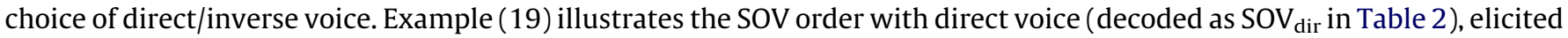
in Condition ' $\mathrm{A}_{\text {giv }} \& \mathrm{P}_{\mathrm{an}}$ '.

$$
\begin{aligned}
& \text { [sc-1] domer jek shäng klara. [sc-2] domer jek shäng } \\
& \text { man go stand CL.ANIM-one man go stand } \\
& \text { dulas poyo-no pang komo. } \\
& \text { boy lift-PFV hang up } \\
& \text { '[sc-1] A man is walking. [sc-2] A walking man threw a boy high up.' }
\end{aligned}
$$

\footnotetext{
${ }^{7}$ An initial data set has been created by the first author in January-July 2006 that served as a basis for formulating hypotheses. The data reported in this article have been collected by both authors in April 2007 in the Térraba Reservation (Puntarenas, Costa Rica). The subjects of the experiments are native speakers of Teribe and bilingual in Spanish. They were born in the Teribe Reservation in Panama and migrated to Costa Rica within the past 2-10 years.
} 
Table 2

Word order results in semi-spontaneous narratives.

\begin{tabular}{|c|c|c|c|c|c|c|c|c|}
\hline & \multicolumn{4}{|c|}{ Agent given } & \multicolumn{4}{|c|}{ Patient given } \\
\hline & \multicolumn{2}{|c|}{ Anim. pat. } & \multicolumn{2}{|c|}{ Inan. pat. } & \multicolumn{2}{|c|}{ Anim. pat. } & \multicolumn{2}{|c|}{ Inan. pat. } \\
\hline & $n$ & $\%$ & $n$ & $\%$ & $n$ & $\%$ & $n$ & $\%$ \\
\hline Total & 32 & & 32 & & 32 & & 32 & \\
\hline Other & 5 & & 6 & & 3 & & 4 & \\
\hline Valid & 27 & 100 & 26 & 100 & 29 & 100 & 28 & 100 \\
\hline $\mathrm{SOV}_{\mathrm{dir}}$ & 26 & 96.3 & 26 & 100 & 9 & 31.1 & 6 & 21.4 \\
\hline $\mathrm{S}, \mathrm{O}, \mathrm{V}_{\mathrm{inv}}$ & 1 & 3.7 & - & - & - & - & - & - \\
\hline $\mathrm{OV}_{\text {inv }} \mathrm{S}$ & - & - & - & - & 19 & 65.5 & 17 & 60.7 \\
\hline $\mathrm{OV}_{\mathrm{inv}}$ & - & - & - & - & 1 & 3.4 & 5 & 17.9 \\
\hline
\end{tabular}

The inverse construction is illustrated in (20), elicited in Condition ' $\mathrm{P}_{\text {giv }} \& \mathrm{P}_{\mathrm{an}}$ '. The word order is OVS and the verb is marked for inverse voice (decoded as $\mathrm{OV}_{\text {inv }} \mathrm{S}$ in Table 2). The postverbal agent is accompanied by the obviative marker $d \ddot{e}$.

(20) [sc-1] dlibapkwo jong kw-ara kingo shko kwozir-wa

table stand CL.ROUND-one on in child-DIM

wale shäng kl-ara. [sc-2] kwozir-wa shäng li

woman stand CL.ANIM-one child-DIM stand REL

bapkwo kingo li poska-ra domer kl-ara dë.

table on REL push-PFV.INV man CL.ANIM-one OBV

'[sc-1] A little girl is standing on a table. [sc-2] A man pushed the girl that was standing on the table.'

Some descriptions display the OV order with a $\mathrm{V}$ in inverse voice (decoded as $\mathrm{OV}_{\text {inv }}$ in Table 2). The use of inverse voice without a realized agent NP denotes the existence of a non-specific agent which is performing the encoded action (see (21), elicited in Condition ' $\mathrm{P}_{\text {giv }} \& \mathrm{P}_{\text {in }}$ ').

$\begin{array}{lllll}\text { [sc-1] } & \text { dlidyorbapkwo } & \text { buk } & \text { kw-ara. } & \text { [sc-2] dlidyorbapkwo } \\ \text { barrel } & \text { lie } & \text { CL.ROUND-one } & \text { barrel } \\ \text { buk } & k w \text {-ara } & \text { li } & \text { poyo-na pang komo. } \\ \text { lie } & \text { CL.ROUND-one } & \text { REL lift-IPFV.INV hang high }\end{array}$

'[sc-1] There is a barrel. [sc-2] Somebody is lifting the barrel that was lying there.'

Finally, a single description elicited in Condition ' $\mathrm{A}_{\text {giv }} \& \mathrm{P}_{\mathrm{an}}$ ' illustrates a complex sentence structure (decoded as $\mathrm{S}, \mathrm{O}, \mathrm{V}_{\mathrm{inv}}$ in Table 2). Both subject and object are left-dislocated, as the presence of the resumptive pronoun $e$ 'that' indicates.

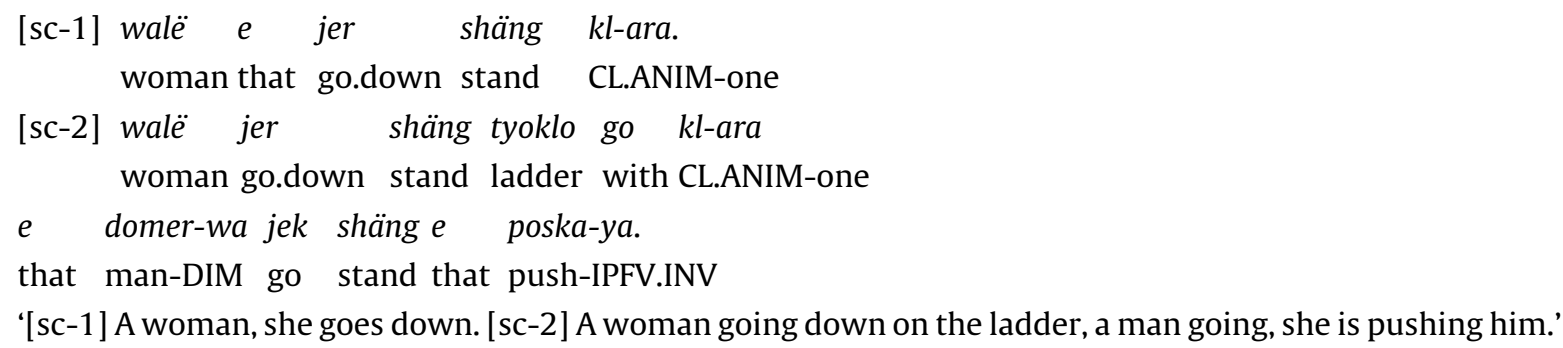

The percentages of valid sentences that involve a verb in inverse voice are presented in Fig. 1. A repeated-measures analysis of variance was carried out on the arcsin-root transformed percentages of inversion; this test revealed a significant main effect for discourse status $\left(F_{1,3}=129.1, p<.001\right.$ pro subjects; $F_{1,7}=209.6, p<.001$ pro items $)$. There was no significant main effect of ontological status $\left(F_{1,3}=.7, p^{*}\right.$ pro subjects; $F_{1,7}=.1, p^{*}$ pro items $)$ and no significant interaction between the two factors $\left(F_{1,3}=1.4, p^{*}\right.$ pro subjects; $F_{1,7}=.9, p^{*}$ pro items).

\subsection{Discussion}

The obtained results confirmed the hypotheses derived from the previous literature on Teribe (Quesada, 2000). The discourse status of the referents has a strong influence on the choice of voice, which is in accordance with the view that inversion in Teribe is pragmatically conditioned. The effect size that we obtained with this experimental manipulation is larger than the effect that Christianson and Ferreira (2005:121) obtained by means of agent and patient questions in another 


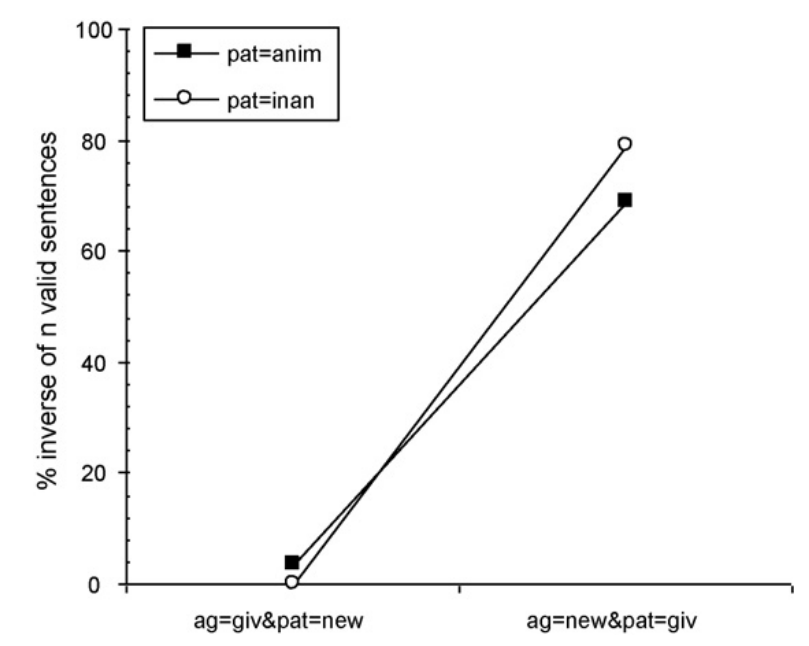

Fig. 1. The impact of discourse status and ontological status on inverse voice.

language with inverse voice, namely Odawa (Algonquian). The experimental condition that induces inverse in Teribe induces passivization in languages such as English, German, French, Dutch, and Yucatec Maya (see Skopeteas and Fanselow, 2009a). Example (23) illustrates the use of passives in Condition ' $\mathrm{P}_{\text {giv }} \& \mathrm{P}_{\mathrm{an}}$ ' in American English.

[sc-1] A man is sitting on a tennis court.

[sc-2] And he is approached by and kicked by a little boy.

The factor 'ontological status' does not have an effect, which is also in line with previous observations on this language (see Quesada, 2000). We mentioned in section 4.1 that if further asymmetries between the involved referents (such as the age group asymmetry discussed with respect to the item in (16)) had an effect, this would be manifested through the production of an amount of inverse clauses across contextual manipulations. This is not the case, since the only sentence with inversion in the Condition ' $A_{\text {giv }} \& \mathrm{P}_{a n}$ ' is the example of left dislocation illustrated in (22).

A comment with respect to the implications of the result on ontological status is at issue. The absence of effect in our data shows that the obviative (agent) can outrank the proximate (patient) in animacy hierarchy, if inverse voice is licensed by the context. Our experiment does not test whether an asymmetry in animacy alone triggers inversion, i.e., it does not test the case in which the patient constituent outranks the agent constituent in animacy, which triggers inverse voice in languages with semantic inversion (see e.g., Aissen, 1999a, on Tzotzil). Previous research shows that this configuration does not trigger inverse voice in Teribe (see Quesada, 2000, for further examples from spontaneously produced narratives).

Under these considerations, the critical condition for the observation of animacy effects is ' $\mathrm{P}_{\text {giv }} \& \mathrm{P}_{\text {in }}$ ', in which a new animate agent acts upon a given inanimate patient. The givenness asymmetry induces inverse voice in Teribe and results in a construction in which the patient outranks the agent in obviation status, but the agent outranks the patient in animacy hierarchy. If an animacy constraint were at issue, it would eliminate inverse clauses in this condition. This is the case in the American English data. None of the 20 sentences collected in the Condition ' $P_{\text {giv }} \& \mathrm{P}_{\text {in }}$ ' exhibits a passive clause; the new agent is always encoded as subject instead, as illustrated in (24). This result provides evidence for a constraint against configurations in which the non-subject outranks the subject in animacy. Comparing to the reaction of English speakers, the absence of significant main effect of the factor 'ontological status' in Teribe implies that this language does not have a constraint against obviative agents that outrank proximate patients in animacy hierarchy.

$$
\text { [sc-1] A round table is perched on the middle step. }
$$

[sc-2] A girl is pushing the table down the stairs.

We pointed out in section 3.2 that inversion in Teribe is uniquely associated with particular word orders: direct $\leftrightarrow$ SOV; inverse $\leftrightarrow$ OVS. The data pattern obtained in this experiment is in line with the cross-linguistic preference for given information to precede new information (see Clark and Haviland, 1977; Haviland and Clark, 1974), see (25a). The generalizations in (25b) summarize the experimental findings. The subject argument is given information in the Conditions ' $\mathrm{A}_{\text {giv }} \& \mathrm{P}_{\text {an }}$ ' and ' $\mathrm{A}_{\text {giv }} \& \mathrm{P}_{\text {in }}$ ' and the object argument is given information in the Conditions ' $\mathrm{P}_{\text {giv }} \& \mathrm{P}_{\text {an }}$ ' and ' $\mathrm{P}_{\text {giv }} \& \mathrm{P}_{\text {in }}$ '. However, our data set involves a quantitative asymmetry: when the referent of the agent constituent is given, speakers select almost exclusively direct voice; when the referent of the patient constituent is given, speakers select predominantly inverse voice (see Fig. 1). Production data from several languages show that this asymmetric pattern reflects a difference in structural markedness (see Hellmuth and Skopeteas, 2007; Skopeteas and Fanselow, 2009a). The marked structure is only licensed by a restricted number of contexts, while the unmarked one is contextually unrestricted, i.e., it occurs in all contexts to some extent. 
(25) (a) Cross-linguistic pragmatic preference:

$\mathrm{XP}_{\mathrm{GIV}} \succ \mathrm{XP}_{\mathrm{NEW}}$

(b) Results of Experiment I:

$[\mathrm{S}]_{\mathrm{GIV}}[\mathrm{OV}]_{\mathrm{NEW}}>[\mathrm{OV}]_{\mathrm{NEW}}[\mathrm{S}]_{\mathrm{GIV}}$

$[\mathrm{O}]_{\mathrm{GIV}}[\mathrm{VS}]_{\mathrm{NEW}}>[\mathrm{S}]_{\mathrm{NEW}} \mathrm{O}_{\mathrm{GIV}}[\mathrm{V}]_{\mathrm{NEW}}$

The given-first principle in (25a) accounts for the quantitative differences in our data set. However, it does not account for the possibility of examples such as (22), which show inverse voice though both arguments are realized preverbally. Though this pattern is very marginal (one single obtained example), it illustrates a structural possibility of the grammar at issue. We will come back to this issue in section 7.

\section{Narrow focus}

Experiment I shows that inverse voice occurs when the referent of the patient is given information and the agent constituent is part of a broad focus domain. Experiment II examines the effects of narrow focus, i.e., discourse configurations in which the focused part of the clause is an argument and the rest is given information.

\subsection{Method}

The informant is shown four pictures that present simple actions involving an agent and a patient. (S)he is instructed to observe the stimuli and memorize their details. When (s)he is ready, the stimuli are taken away, and four pre-recorded questions are played on the laptop. The informant is instructed to give "full answers to the questions", and not short answers like yes, no, a woman, etc.

The questions used in the experiment induce several focus types (following the taxonomy proposed in Dik, 1997). In particular, four types of answers to questions are examined: (a) answers to constituent questions (inducing "completive" focus in the sense of Dik, 1997); (b) answers to alternative questions (inducing "selective focus", o.c.) and (c) answers rejecting a constituent of a truth value question (inducing "corrective/rejective" focus, o.c.). In order to avoid a priming effect of repeated corrections on truth value questions, a type (d) context was included, namely truth value questions that induce a confirmative answer. Thus, the factor "focus type" contains four levels: $\left\{\right.$ Level $_{1}$ : ${\text { completion; } \text { Level }_{2} \text { : selection; Level }}_{3}$ : rejection; Level $_{4}$ : confirmation\}. This factor was crossed with the factor "focused argument" which contains two levels: \{Level ${ }_{1}$ : agent; Level ${ }_{2}$ : patient\}. Crossing the first three levels of the first factor with the levels of the second factor results into 6 experimental conditions. In case of confirmation, neither constituent is in focus, hence this answer type does not instantiate the two levels of the second factor. The full list of experimental conditions is presented in (26). The questions contained a frame setter which allowed the informant to identify which of the four pictures is at issue.

(26) Stimulus: 'in front of a well, a man is pushing a car'

C/a (completion, agent): 'In front of the well, who is pushing the car?'

$\mathrm{C} / \mathrm{p}$ (completion, patient): 'In front of the well, what is the man pushing?'

S/a (selection, agent): 'In front of the well, is a man or a woman pushing the car?'

$\mathrm{S} / \mathrm{p}$ (selection, patient): 'In front of the well, is the man pushing a car or a bicycle?'

$\mathrm{R} / \mathrm{a}$ (rejection, agent): 'In front of the well, is a woman pushing a car?'

$\mathrm{R} / \mathrm{p}$ (rejection, patient): 'In front of the well, is the man pushing a bicycle?'

F (confirmation): 'In front of the well, is a man pushing a car?'

All question types were implemented in the SOV order as exemplified in (27a) for patient questions and (27b) for agent questions.

(a) klunshosho e kop shko díngding e bokshto
wall that sky in blue that front
domer $e$ shäng $\ddot{e}$ poskak?
man that stand who hit

'In front of the blue wall, whom is the man hitting?'

(b) dibzoklo bokshto ga íp ga ëye sbi sök-do?

bridge front and see-2.SG and who pot carry-PRF

'In front of the bridge, who has carried the pot?'

The conditions in (26) were implemented in 8 items, which were presented in two versions to the informants (these versions involve an animacy manipulation that is not discussed in this article, since it does not reveal any substantial result; 
see details in Skopeteas et al., 2006:99-107). The 16 pictures were distributed in 4 sheets of 4 pictures each. Each sheet was accompanied by four questions belonging to the four focus types alternating between agent and patient questions. Since the confirmation focus type does not distinguish between agent and patient focus, the design included twice as many tokens for Condition ' $F$ '. Hence, the overall design contained $6 \times 8+16=64$ elements. The 64 elements were distributed in the same four sessions with Experiment I and were pseudo-randomized. The subjects of Experiment I participated in this experiment too and were exposed to the full range of experimental elements, which renders a data set of 4 (informants) $\times 64$ (answers) $=256$ answers. This data set contains 64 answers in Condition ' $F$ ' and 32 answers per condition for all further conditions.

The question/answer experiment is expected to allow us for insights concerning the impact of narrow focus on the choice of voice. Based on the results of the Experiment I, we expect that this discourse context will also show an impact of the preference for given-before-new orders. On this basis, all questions that involve agent focus are expected to induce inverse constructions to some extent. Patient focus contexts, on the other hand, are generally expected to be answered through unmarked SOV sentences in direct voice. Finally, confirmative answers do not involve any asymmetry in discourse status; hence we expect to elicit answers in the canonical SOV order and direct voice in this context.

\subsection{Results}

Two types of answers were decoded as "other" and are excluded from further consideration. First, some trials failed to invoke the intended discourse condition. This deviation was frequent in the Conditions 'R/a' and 'R/p': though the truth value question was designed to induce rejection, speakers often confirmed this question, probably due to memory limitations. Furthermore, answers without an overt verb had to be excluded, since these do not allow for observations concerning word order, as shown in (28). In total, 43 out of 256 answers (16\%) were excluded from the obtained data set.

(28) Q: 'In the stone house, who is killing a man?'

A: domer oblë.

man different

'Another man.' (Condition C/a)

The remaining answers constitute the valid data set in which we can observe the distribution of direct and inverse voice. The most frequent answer type (53\% of valid sentences) contains SOV clauses in direct voice (see (29)).

(29) Q : 'Where the sky is blue, do you see if a woman is hitting a man?'

A: wale li domer shpog-do.

woman REL man hit-PRF

'The woman has hit a man.' (Condition F)

Answers with direct voice and without lexically realized subject were encountered as well (13\% of valid sentences); see (30).

(30) Q: 'In front of the blue wall, who is the man pushing?'

A: wale poskak.

woman push

'(He) is pushing a woman.' (Condition $\mathrm{C} / \mathrm{p})$

Two types of clauses with inverse voice have been obtained: (a) complete answers with OVS word order (13\% of valid sentences), see (31); and (b) answers without a lexically realized patient (19\%), see (32).

(31) Q: 'Where the sky is cloudy, who sees the little girl?'

A: kwozir-wa wale shäng $e$ ik domer shäng ba

child-DIM woman stand that see man stand 3.SG

slongbang dë.

side OBV

'The girl, a man who is at her side sees her.' (Condition C/a)

(32) Q: 'Where the blue sky is, did a woman or man hit the man?'

A: yo-ga domer dë.

hit-IPFV.INV man OBV

'A man hit.' (Condition S/a) 
Table 3

Answers obtained in Experiment II.

\begin{tabular}{|c|c|c|c|c|c|c|c|c|c|c|c|c|}
\hline & \multicolumn{4}{|c|}{ Completion } & \multicolumn{4}{|c|}{ Selection } & \multicolumn{4}{|c|}{ Rejection } \\
\hline & \multicolumn{2}{|c|}{ Patient } & \multicolumn{2}{|c|}{ Agent } & \multicolumn{2}{|c|}{ Patient } & \multicolumn{2}{|c|}{ Agent } & \multicolumn{2}{|c|}{ Patient } & \multicolumn{2}{|c|}{ Agent } \\
\hline & $n$ & $\%$ & $n$ & $\%$ & $n$ & $\%$ & $n$ & $\%$ & $n$ & $\%$ & $n$ & $\%$ \\
\hline Total & 32 & & 32 & & 32 & & 32 & & 32 & & 32 & \\
\hline Other & - & & 1 & & 1 & & 5 & & 18 & & 12 & \\
\hline Valid & 32 & 100 & 31 & 100 & 31 & 100 & 27 & 100 & 14 & 100 & 20 & 100 \\
\hline $\mathrm{SOV}_{\mathrm{dir}}$ & 24 & 75 & 8 & 25.8 & 15 & 48.4 & 2 & 7.4 & 10 & 71.4 & 5 & 25 \\
\hline$O V_{\text {dir }}$ & 6 & 18.8 & - & - & 14 & 45.2 & - & - & 4 & 28.6 & - & - \\
\hline $\mathrm{OV}_{\text {inv }} \mathrm{S}$ & 2 & 6.2 & 8 & 25.8 & 2 & 6.4 & 8 & 29.6 & - & - & 7 & 35 \\
\hline $\mathrm{V}_{\text {inv }} \mathrm{S}$ & - & - & 15 & 48.4 & - & - & 17 & 63 & - & - & 8 & 40 \\
\hline
\end{tabular}

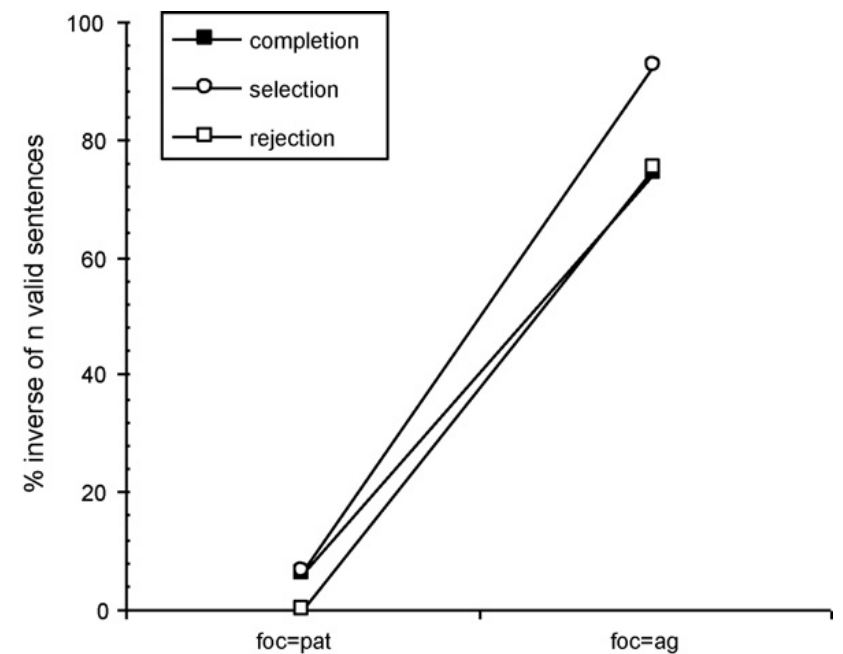

Fig. 2. Focus type vs. focused argument in semi-spontaneous answers.

The quantitative results are summarized in Table 3. Confirmation answers are not presented in the table: apart from 6

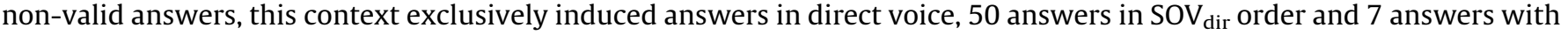
subject ellipsis $\left(\mathrm{OV}_{\mathrm{dir}}\right)$.

Fig. 2 gives an overview of the proportion of valid sentences which exhibit inverse voice in the conditions that provide evidence for the interaction between focus type and focused argument. A repeated-measures analysis of variance on the arcsin-root transformed proportions revealed a significant main effect of focused argument $\left(F_{1,3}=336.4, p<.001\right.$ pro subjects; $F_{1,7}=119.1, p<.001$ pro items $)$, but no significant effect for focus type $\left(F_{2,2}=.003, p^{*}\right.$ pro subjects; $F_{2,6}=3.4, p^{*}$ pro items) nor for the interaction among the two factors $\left(F_{2,2}=.9, p^{*}\right.$ pro subjects; $F_{2,6}=.6, p^{*}$ pro items).

\subsection{Discussion}

Teribe speakers choose inversion in all contexts that induce narrow focus on the agent. The exact focus type does not have any significant effect on the choice of voice. We have seen in section 4.3 that inverse voice in Teribe has the same distribution as passive voice in European languages such as English, German, or French. However, the present experiment, which also induces inverse voice in Teribe, does not induce passive in the compared languages. It induces cleft constructions in some languages, e.g., English and French, or movement to the focus position in other languages, e.g., Hungarian and Georgian (see a comparative study on these four languages in Skopeteas and Fanselow, 2009b). Example (33a) illustrates the occurrence of clefts in American English and (33b) illustrates the movement of the focused constituent to the preverbal position in Hungarian (the canonical position for subjects being postverbal in this language, see Kiss, 1998). This data shows a clear distributional difference between inverse voice in Teribe and passive voice in familiar languages. The crucial difference is that inverse voice is also invoked by narrow focus on the agent constituent.

\section{(a) English}

Q: 'In front of the well, is a man pushing the man?

A: No, it is a guy pushing the man. 
(b) Hungarian

Q: 'There, where the cloudy sky is: is a woman looking at the girl?'

A: Nem, egy férfi néz a lány-ra.

no INDEF man look.PRS:3.SG DEF girl-SUBL

'No, a man is looking at the girl.'

The quantitative differences observed under narrow focus manipulations are in line with the observations from Experiment I. Hence, the summarized findings in (34) can be accounted for through the given-first principle in (25a).

$$
\begin{aligned}
& \text { Results of Experiment II: } \\
& {[\mathrm{S}]_{\mathrm{GIV}}[\mathrm{O}]_{\mathrm{FOC}}[\mathrm{V}]_{\mathrm{GIV}}>[\mathrm{O}]_{\mathrm{FOC}}[\mathrm{VS}]_{\mathrm{GIV}}} \\
& {[\mathrm{OV}]_{\mathrm{GIV}}[\mathrm{S}]_{\mathrm{FOC}}>[\mathrm{S}]_{\mathrm{FOC}}[\mathrm{OV}]_{\mathrm{GIV}}}
\end{aligned}
$$

However, a number of counterexamples have been encountered in both conditions. Similarly to the result of the previous experiment (see discussion in 4.3), the occurrence of SOV sentences in the conditions of agent focus is not surprising since SOV is the basic word order in the language (see Table 3, 17 out of 40 sentences with two lexically realized arguments, i.e., 42.5\%). What was merely unexpected was the occurrence of OVS sentences in the conditions that induce narrow focus on the patient constituent (see Table 3, 4 out of 53 sentences with two lexically realized arguments, i.e., 7.5\%). The occurrence of these sentences motivates the hypothesis that the choice between direct and inverse voice does not exclusively depend on the effects of the given-first principle. This hypothesis is the subject of the following section.

\section{Pragmatic underspecification}

The data presented so far suggests a strong preference to use inverse voice when the patient constituent outranks the agent constituent in givenness, but this generalization does not account for the counterexamples that we encountered in both experiments. In this section, we show that the pragmatic generalization of section 5.3 should be understood as a strong preference but not as an inherent property of the voice alternation in Teribe. We argue (a) that inverse voice is a syntactic operation determining the alternation between two alternative linearizations of the clausal arguments (SOV vs. OVS) and (b) that the selection of voice in discourse depends on an array of factors that include the given-first principle.

In Experiment II, we encountered some instances of inverse voice with narrow focus on the object. Example (35) is illustrative: the narrow focused object is the proximate argument and the given agent is the obviative argument.

$$
\begin{aligned}
& \text { Q: 'In front of the bridge, what is the man carrying?' } \\
& \text { A: kwozir-wa wale sö-ydë domer dë. } \\
& \text { child-DIM woman carry-PROSP man OBV } \\
& \text { 'The man is carrying a girl.' }
\end{aligned}
$$

Examples like (35) suggest that the proximate argument is not necessarily given information. The observed tendencies may be the result of pragmatic principles which are independent of syntax and which determine the choice of linearization in this language. This view is supported by two additional pieces of evidence. The first comes from constituent questions. Interrogative pronouns are realized in situ in Teribe (see Quesada, 2000:102). Example (36) shows that there are no constraints on their occurrence in patient or agent positions in either direct or inverse constructions, which shows that any constituent in both orders may host presupposed information. The critical example is (36c): If the proximate argument in inverse voice, i.e., the object, were unambiguously associated with the given part of the utterance, (36c) would be ungrammatical, which is not the case.

(36) (a) Direct voice, subject question

$$
\begin{aligned}
& \text { ëye shäng domer yok? } \\
& \text { who stand man hit }
\end{aligned}
$$

'Who is hitting the man?'

(b) Direct voice, object question

$$
\begin{array}{lll}
e & \text { domer shäng llë të? } \\
\text { that man stand what kick }
\end{array}
$$

'What is that man kicking?' 
(c) Inverse voice, object question

$\begin{array}{lll}l l e ̈ & \text { sö-ya } & \text { domer } \\ \text { what } & \text { carry-IPFV.INV man } & \text { OBV belong }\end{array}$

'What is the man carrying?'

(d) Inverse voice, subject question

$\begin{array}{llll}\text { nana sö-ya } & \ddot{e} y e & \text { dë shäng? } \\ \text { flower carry-IPFV.INV who } & \text { OBV stand }\end{array}$

'Who is carrying the flower?'

Further evidence comes from quotative inversion. Quotative inversion is among the constructions that induce noncanonical word orders even in languages with rigid word order such as English or French. ${ }^{8}$ Since the preposed quotation is an object constituent, this construction obligatorily induces inverse voice in Teribe, as illustrated in (37). Quotative inversion is independent of the discourse status of the subject.

$$
\begin{aligned}
& \text { "Orkwo zeng” } e \text { le tlapga-ga dë } \\
& \text { hand cold that say.IPFV.INV elder-PL OBV } \\
& \text { "“Their hands were cold" said the elders.' (Quesada, 2000:126) }
\end{aligned}
$$

The examples in this section show that the hypothesis that inversion is unambiguously associated with a particular pragmatic configuration cannot be maintained. A narrow focused object constituent or an interrogative pronoun can be selected as the proximate argument in discourse. The word order in quotative constructions shows that factors that do not relate to information structure can license inversion too (in this case, a preference against embedding the quotation between $\mathrm{S}$ and $\mathrm{V}$ ). On the basis of this evidence, we assume that inverse voice in this language is a structural means to achieve two alternative linearizations of the clausal arguments and is not categorically associated with a particular information structural function (such as proximate $\leftrightarrow$ topic). This statement does not imply that the occurrence of voice in discourse is random. The choice of linearization is determined by the competition of pragmatic principles that apply on the linear order. It is cross-linguistically known that clause initial constituents are ideal carriers for a 'prominent' function in discourse. The exact information state of the prominent constituent (topic or focus) is not specified. In a narrative (as in Experiment I), the most prominent function is probably the link to the already established common ground, i.e., the topic. In this context, inverse voice occurs when the object constituent is given information. Single examples such as (35) in Experiment II show that object initial clauses are also licensed when the object constituent is the variable under question. Note that inverse constructions with focused object constituents have been encountered when the object is in a narrow focus domain (as in Experiment II), but not when the object is part of a broader focus domain (as in Experiment I). Hence, our result suggests a influence of the focus domain: A narrow focus is more likely to induce a ffocus, background \}articulation than a broad focus. The examples in (33) show that narrow focus induces constructions that match to the \{focus, background articulation in English, French, and Hungarian. In Teribe, the only structural possibility to front focused objects is the inverse voice and the concomitant OVS order. Hence, it is not surprising that this construction appears in the corresponding context.

\section{Incremental choice of voice}

In Experiment I, we found a counterexample to the generalization that an SOV order is associated with direct voice (see (22) above). As already mentioned in section 4.2, both verbal arguments are left-dislocated (since they are cross-referenced by the pronoun $e$ ). Hence, though the constituents appear in a linearization that is identical to the SOV order, this example is not a genuine instance of the canonical syntactic configuration, since $\mathrm{S}$ and $\mathrm{O}$ are extraposed. The question is whether this fact may explain the occurrence of inverse voice in this example.

We have argued in section 6 that the choice among a direct and an inverse construction is determined by the competition of the available arguments in prominence. In order to understand examples like (22), we must identify the discourse unit that determines the competition between the available referents in prominence. The most explicitly articulated account of the interaction between discourse units and obviation functions is Aissen (1997, 2000). Within this framework, discourse is organized in obviation spans, which are the maximal units of continuous discourse in which the obviation statuses (proximate, obviative) remain unaltered. The obviation statuses are determined as follows: the most prominent referent occupies the proximate function, while the further referents have the obviative (or non-proximate) function. The choice of direct/inverse voice depends on the functions of the arguments within the encompassing obviation span: whenever the most prominent referent (proximate) is the subject constituent, direct voice is used, while whenever the most prominent referent

\footnotetext{
${ }^{8}$ Vgl. French “Ce n'est pas de sa faute", semblait voiloir dire Marie aux policiers (Bonami et al., 1999), English "I am so happy" thought Mary. (Collins and Branigan, 1997); compare also the obligatoriness of quotative inversion in languages with free word order such as Albanian, Modern Greek, and SerboCroatian (Matić, 2003).
} 
is the object constituent, inverse voice is chosen instead. Establishing an obviation span for parts of a narrative is a means to create coherence and allows for reference tracking of third person nominals. For instance, the obviation span which begins in [sc-2] in (38) contains the following referents: proximate $=\{$ little.man $\}$, non-proximates $=\{$ little.girl, stock $\}$. In the first sentence of [sc-3], the referent in proximate function is the subject of the clause, hence direct voice is used. In the second clause, the same referent maintains is the object constituent, which results in inverse voice.

(38) [sc-1] 'Next to a bush appeared a girl and behind her a little man holding a stick.' [sc-2] 'The little man gave it to the little girl and...'

[sc-3] domer-wa bo-jong jek iröng juni shko ga shpo-gz-a

man-DIM turn-PFV go again here in and hit-SUBIT-3.SG

ba walë-wa li dë ba k'or li go

3.SG.POSS woman-DIM TOP OBV 3.SG.POSS stick TOP with

ba dlu ro shko.

3.SG.POSS head inside in

'. . the man turned around and he is suddenly hit with the stick on the head by the little woman.'

The crucial issue is the identification of the minimal discourse unit which may serve as an obviation span in a given language (see Aissen, 1997). By definition, an obviation span may not be smaller than a clause, but - as the next examples show - it can be smaller than a sentence. The critical evidence comes from subordinate clauses, since they exemplify the syntactic condition 'same sentence and different clause'. When the subject of the subordinate clause is identical to the subject of the matrix clause, there is a strong preference for the direct construction, which results from the fact that there is no obvious reason to abandon the established relations in the obviation span.

(a) Maria e om midë ga e Juan shpo-no.

Maria that FOC know that that Juan hit-PFV

'Maria knows (it), that she hit Juan.' (preferred)

(b) Maria $e$ om midë ga Juan shpo-ga $e$ dë.

Maria that FOC know that Juan hit-IPFV.INV that OBV

'Maria knows (it), that Juan was hit by her.' (non-preferred, but possible)

The reverse situation appears when the subject of the matrix clause is the object of the subordinate clause. In this case, there is a strong preference for the inverse construction.
(a) Maria e om midë ga e shpo-ga Juan dë.
Maria that FOC know that that hit-IPFV.INV Juan OBV
'Maria knows (it), that she is hit by Juan.' (preferred)
(b) Maria e om midë ga Juan om shpo-no.
Maria that FOC know that Juan FOC hit-PFV
'Maria knows (it), that Juan hit her.' (non-preferred, but possible)

The examples (39b) and (40b) show that it is grammatically possible (though not the preferred option) to renovate the association between referents and obviation functions within the limits of the sentence. Having established that an obviation span can be smaller than a sentence, we assume that this property accounts for examples like (22). Since the arguments are extra-clausal, a change of the obviation span is possible. Further examples in our corpus support this hypothesis. In (41), the man is the current discourse topic and hence occupies the proximate function at the beginning of the utterance. The patient constituent that follows is left-dislocated. Crucially, the verb exhibits inverse morphology which suggests that the object occupies the proximate function at the critical moment in discourse when the speaker selects the voice of the verb.

(41) [sc-1] 'There is a man holding a cigarette; an apple on the table; he is looking at it.'

[sc-2] domer li wloshko duwo teng plunshoshobapkwo

man TOP holding cigarette belong bowl

e $\quad \tilde{\imath}-y a \quad$ shäng.

that see-IPFV.INV stand

'The man is holding a cigarette and looking at the bowl.' 
Such examples motivate the hypothesis that the choice of voice in Teribe does not refer to a fixed prominence hierarchy within the broader discourse span, but it is determined incrementally during speech production. In order to check this hypothesis, a further experiment was performed, which is presented in the subsequent sections.

\subsection{Method}

The experiment presented in this section is an orally performed completion task. The informant is shown a picture while a pre-recorded sound file is displayed on the laptop. (S)he is instructed that (s)he will hear an incomplete description of the picture and that his/her task is to complete it. The sound files contain descriptions of the pictures in SOV order whose final constituent, i.e., the verb, is cut off as illustrated in (42). The informant fills in the missing information orally.

(42) Visual stimulus: 'a man is looking at a girl'

Auditive stimulus:

domer shäng kl-ara koglo...

man stand CL.ANIM-one girl

'A man ... a girl.'

The research question is whether the choice of inverse voice is sensitive to the incrementality of speech production or not. If it does, we expect that grammatical and extra-grammatical factors which influence the prominence of the arguments at the critical point of the articulation of the verb will have an impact on the choice of voice. Two factors were examined in the experimental design. First, we examined a grammatical factor, namely the clausal extraposition of the arguments, by adding a resumptive pronoun $e$ 'that' as illustrated in (43) (compare with (42)). The presence of the pronoun implies that the object argument is left-dislocated and - by consequence - the subject argument too. Hence, the factor 'argument extraposition' has two levels: \{extraposed arguments, non-extraposed arguments\}.

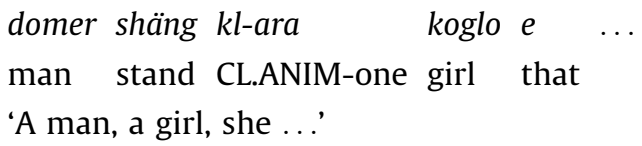

This factor was crossed with an extra-grammatical factor, namely the 'subject-verb distance', also comprising two levels: \{long, short\}. We manipulated subject-verb distance by using heavy vs. light object constituents. Examples (42) and (43) illustrate the stimuli with light objects. The corresponding stimuli with heavy objects are illustrated in (44a) for nonextraposed arguments and (44b) for extraposed arguments.

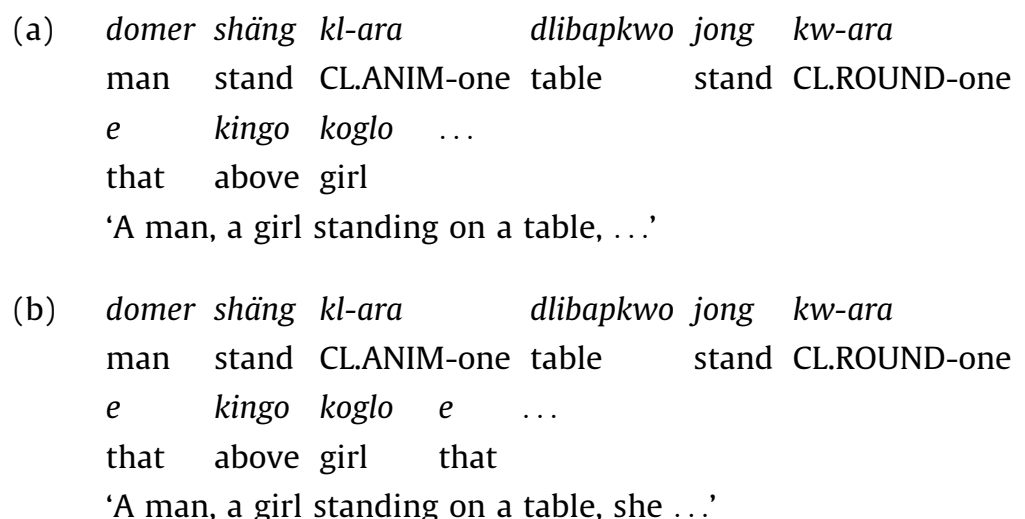

Crossing the factors 'argument extraposition' and 'subject-verb distance' results in four experimental conditions. All conditions were implemented in four items, each containing a different action with two animate participants. For the visual presentation of the event, we have used four pictures from Experiment I. For the development of auditive stimuli, we recorded full descriptions of the pictures (also containing the final verb), so that our stimuli display the prosodic structure of a complete utterance, and we removed the verb from the stimulus file. Recordings were made with one of the four speakers (FAC) on a DAT recorder (SONY 100) and were digitized and cut in Praat (Boersma and Weenink, 2006).

The overall experiment contained ( 4 conditions $\times 4$ items $=$ ) 16 elements, which were distributed in 4 experimental sessions, such that each session contains each item and each condition once. The tasks of this experiment were performed in the intervals of a longer experimental session containing two further experiments that were very different in nature. Each informant was exposed to all 16 tasks of this experiment. 
On the basis of our observations, we assume that the speaker chooses among a direct and an inverse verb form at the critical moment of having parsed the whole stimulus, which includes both arguments. The availability of a resumptive pronoun occupying the object slot suggests that the preceding arguments have an extra-clausal status. The sole inner-clausal argument in the construction illustrated in (43) and (44b) is the pronominal object. Assuming that the sole inner-clausal argument is highly prominent while the speaker spontaneously selects voice, we expect that this experimental condition will induce inversion. Subject-verb distance, manipulated through the weight of the object constituent, has an effect on the prominence of the subject argument. The basic assumption is that a remote subject is less prominent at the moment that the speaker selects voice. In this view, we expect that the speaker will go for the inverse form whenever the subject is remote. If both predictions will be born out, we expect to get a cumulative effect of the impact of both factors in the Condition 'extraposed \& long subject-verb distance', in which both prominence reducing factors are harmonically combined (see (44b)).

\subsection{Results}

In most cases, the informants have added only a verb to the non-complete utterance, necessarily choosing among a direct and an inverse verb form, see (45).
(a) Stimulus: domer shäng kl-ara koglo ...
man stand CL.ANIM-one girl
'A man ... a girl.'
(b) Reaction: ... poskak.

$$
\begin{aligned}
& \text { push } \\
& \text { '... pushes.' }
\end{aligned}
$$

In some other cases, informants have repeated the last constituent, i.e., the patient as illustrated in (46). These responses are valid data for the hypotheses at issue, since they do not change the configuration of the involved factors.

$$
\begin{aligned}
& \text { (a) Stimulus: domer shäng kl-ara koglo } e \quad \ldots \\
& \text { 'A man, a girl, ... her' } \\
& \text { (b) Reaction: ... koglo e poskak. } \\
& \text { girl that push } \\
& \text { '. . . a girl, (he) pushes her.' }
\end{aligned}
$$$$
\text { man stand CL.ANIM-one girl that }
$$

The obtained results are summarized per speaker in Table 4. Note that the choice of inverse constructions increases according to our predictions. The patterns of the four speakers are similar with the exception of the preference of speaker FAC for direct and the preference of speaker MAR for inverse voice in the Condition 'extraposed \& long subject-verb distance'. We

\begin{tabular}{|c|c|c|c|c|c|c|c|}
\hline & & Informant & $\mathrm{ADE}$ & FAC & FLO & MAR & Sum \\
\hline & & Total & 16 & 16 & 16 & 16 & 64 \\
\hline \multirow[t]{4}{*}{ Short } & -Extraposed & Direct & 4 & 4 & 4 & 3 & 15 \\
\hline & & Inverse & - & - & - & 1 & 1 \\
\hline & Extraposed & Direct & 3 & 3 & 3 & 3 & 12 \\
\hline & & Inverse & 1 & 1 & 1 & 1 & 4 \\
\hline \multirow[t]{4}{*}{ Long } & -Extraposed & Direct & 2 & 4 & 3 & 2 & 11 \\
\hline & & Inverse & 2 & - & 1 & 2 & 5 \\
\hline & Extraposed & Direct & 2 & 3 & 2 & 1 & 8 \\
\hline & & Inverse & 2 & 1 & 2 & 3 & 8 \\
\hline
\end{tabular}
assume that this difference is the result of random variation and does not reveal a difference in the discourse strategies that these speakers prefer.

Descriptively speaking, the observed proportions are in line with our expectations, see Fig. 3. A repeated-measures analysis of variance on the arcsin-root tranformed proportions revealed a significant main effect for 'SV distance' $\left(F_{1,3}=26.3\right.$;

Table 4

Choice of verb form in sentence completion task. 


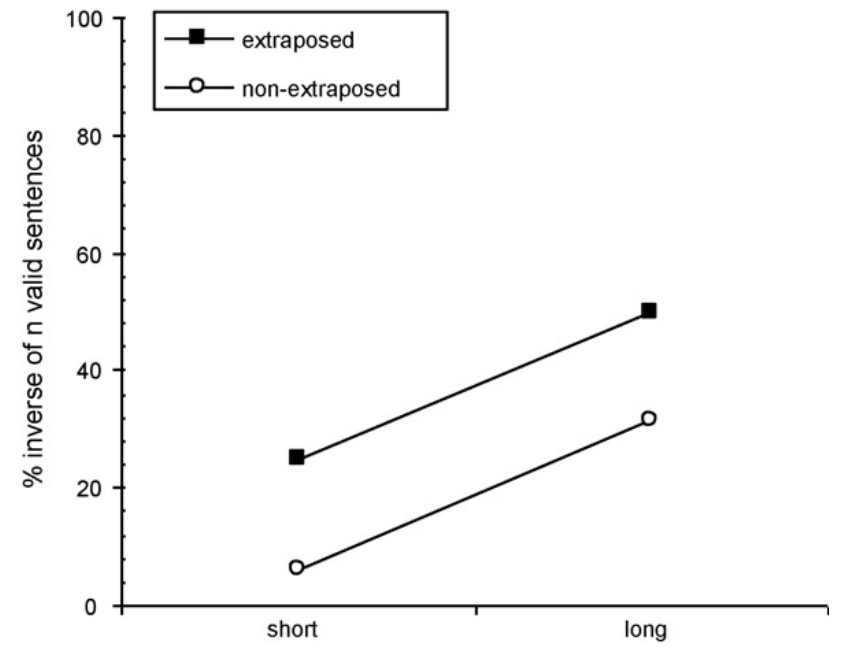

Fig. 3. Grammatical and extra-grammatical influences on choice of inversion.

$p<.05$ pro subjects; $F_{1,3}=23.9 ; p<.05$ pro items). The factor 'extraposition' was only marginally significant in the analysis pro subjects $\left(F_{1,3}=8.1, p<.06\right)$, however did not reach significance in the analysis pro items $\left(F_{1,3}=5.3, p<.1\right)$. The interaction between the factors is not significant $\left(F_{1,3}=.002, p^{*}\right.$ pro subjects; $F_{1,3}=.001, p^{*}$ pro items). It is important to note that the descriptive data shows the predicted pattern. We assume that the failure to exclude the null hypothesis at the adopted significance level is due to the limited $n$ of subjects in our sample (which however cannot be expanded due to the field's limitations: no more than four native speakers that could participate in this kind of experiments are living in the Térraba reservation).

\subsection{Discussion}

This experiment confirmed our expectation that the choice of inverse is influenced by factors that determine the relative prominence of the arguments at the critical moment that the speaker selects voice. Hence, the single counterexample that we have gained in Experiment I is not the result of random choice of voice but reflects the incremental properties of discourse prominence.

The delimitation of an obviation span is influenced during language production by grammatical and extra-grammatical factors. An exhaustive identification of the factors and the patterns of their interaction is beyond the purposes of our article. The factors at issue were chosen in order to answer the question whether the limits of an obviation span are solely determined by the syntactic configuration or not. The results show that both factors have an effect, but only the effect of the extra-grammatical factor 'distance' reached statistical significance. These findings have radical consequences for our understanding of the factors that determine obviation in discourse. The relative prominence is dynamically determined in discourse and local changes in prominence influence the choice of direct vs. inverse voice.

The significant main effect of subject-verb distance is striking, because it is in conflict with the basic assumption that an obviation span may not be smaller than a clause. There are two possible explanations to this conflict: either the basic assumption does not hold true for the incremental processing of speech production, since the speaker does not necessarily plan the entire clause from the beginning of his/her utterance, or our stimuli invoke the interpretation that the subject is extraposed. These possibilities create an empirical question for future research.

\section{Conclusions}

The aim of this article is to offer a better understanding to the discourse functions of inversion. We first presented two production experiments which allow us to identify the discourse situations in which Teribe speakers select inverse voice and to compare the functions of inversion to further syntactic constructions which are influenced by information structure. After concluding that discourse prominence accounts for the choice of voice in this language, we presented the results of a completion experiment which examines the interaction of discourse prominence with the incremental properties of speech production.

Extending previous accounts on Teribe, we have shown that inverse voice does not have an influence to the syntactic function of the involved arguments. A crucial property of this construction is that it is associated with word order: SOV (direct voice) and OVS (inverse voice). Pragmatic factors that influence the linear order of the conveyed information are expected to have a direct impact on the choice of voice in this language.

The first experiment has shown that inversion in Teribe is determined by the discourse status of the arguments and has confirmed previous observations (Quesada, 2000) that ontological status does not influence the choice of voice in this language. In particular, there is a strong preference to select the given argument as proximate. Given that proximate 
arguments are clause initial in Teribe, this result may be explained by the universal pragmatic preference for given information to precede new information. In cross-linguistic perspective, the effect of givenness on the choice of inverse voice in Teribe is comparable to the effect of givenness on the choice of passive voice in European languages.

The second experiment examined the effect of narrow focus on the choice of inversion. In line with the results from the first experiment, a strong preference for given information to precede new has been observed. This result shows that this preference outranks the preference to place the narrow focused constituent in an early place in the sentence, which results in cleft clauses in English and French or in movement to a focus position in a language like Hungarian. However, the result in Teribe was not categorical: a few instances of inversion were encountered in answers containing object focus too. After a discussion of further facts from question formation and quotative inversion, we concluded that inversion is not unambiguously associated with a particular information structure, i.e., the proximate argument is not necessarily the topic. We argued that the proximate argument hosts the most prominent referent and that discourse prominence can reflect different information structural concepts.

Finally, we addressed the question how prominence operates for the selection of obviation functions. Our evidence supports the view that prominence is dynamically determined during speech production. In particular, our experiment has shown that a non-syntactic factor such as subject-verb distance has a significant effect on the choice of voice. This observation supports the view that the competition of the referents in prominence determines the choice of voice at the critical moment in which the speaker selects the verb.

It is not easy to judge whether the findings in Teribe could be generalized for inverse voice cross-linguistically. It has to be noted that inversion in Teribe is categorically associated with particular word orders and this only applies for a subset of the languages with inverse systems. A second cross-linguistic factor that may interact with the choice of voice is the availability of paradigmatic alternatives (such as cleft sentences or the possibility to place constituents in information structurally conditioned positions). It is crucial for Teribe that inversion is practically the only available option for the manipulation of the linear order of clausal arguments.

At the very beginning of this article, we referred to the current skepticism concerning the association of particular grammatical structures with information structural concepts. Our empirical study on inverse voice adds evidence to this view. The association between proximate arguments and topics is not categorical, but it is determined by the interaction of pragmatic preferences for linearizing the conveyed information in an order which is optimal for the addressee. These preferences have an influence on the choice of syntactic constructions in discourse but are not inherent properties of syntax.

\section{Acknowledgments}

This article is a product of project D2 Typology of Information Structure, which is part of the SFB Information Structure at the University of Potsdam/Humboldt University of Berlin. We wish to thank Gisbert Fanselow and Caroline Féry for their discussion during the development of the experiments and the interpretation of this data, our Teribe informants, Faciano Vargas, Adelfia González, Florencio Gamarra, and Marlene Aguilar, as well as an anonymous reviewer for helpful comments.

\section{References}

Aissen, Judith, 1997. On the syntax of obviation. Language 73 (4), 705-750.

Aissen, Judith, 1999a. Agent focus and inverse voice in Tzotzil. Language 75 (3), 451-485.

Aissen, Judith, 1999b. Markedness and subject choice in optimality theory. Natural Language and Linguistic Theory $17,673-711$.

Aissen, Judith, 2000. yi and bi: proximate and obviative in Navajo. In: Carnie, Andrew, Jelinek, Eloise, Willie, Mary (Eds.), Papers in Honor of Ken Hale, MIT Working Papers on Endangered and Less Familiar Languages 1, 129-150.

Boersma, Paul, Weenink, David 2006. Praat (Version 4.5) [computer program], retrieved from www.praat.org.

Bonami, Olivier, Godard, Danièle, Marandin, Jean-Marie, 1999. Constituency and word order in French subject inversion. In: Bouma, Gosse, Hinrichs, Erhard, Kruijff, Geert-Jan M., Oehrle, Richard (Eds.), Constraints and Resources in Natural Language Syntax and Semantics. CSLI Publications, Stanford/CA, pp. 21-40.

Chafe, Wallace, 1994. Discourse, Consciousness, and Time: The Flow and Displacement of Conscious Experience in Speaking and Writing. The University of Chicago Press, Chicago.

Christianson, Kiel, Ferreira, Fernanda, 2005. Conceptual accessibility and sentence production in a free word order language (Odawa). Cognition 98, 105135.

Clark, Herbert H., Haviland, Susan E., 1977. Comprehension and the given-new contract. In: Freedle, Roy O. (Ed.), Discourse Production and Comprehension. Erlbaum, Hillsdale/NJ, pp. 1-40.

Collins, Chris, Branigan, Phil, 1997. Quotative inversion. Natural Language and Linguistic Theory 15, 1-41.

Cooreman, Ann, 1987. Transitivity and Discourse Continuity in Chamorro Narratives. Mouton de Gruyter, Berlin.

Dik, Simon C., 1980. Studies in Functional Grammar. Academic Press, London etc.

Dik, Simon C., 1997. The Theory of Functional Grammar. Mouton de Gruyter, Berlin/New York.

Dixon, R.M.W., Aikhenvald, Alexandra, 1997. A typology of argument-determined constructions. In: Bybee, Joan, Haiman, John, Thompson, Sandra (Eds.), Essays on Language Function and Language Type. Dedicated to T. Givón. Benjamins, Amsterdam, pp. 71-113.

Du Bois, John W., 1987. The discourse basis of ergativity. Language 63 (4), 805-855.

Fanselow, Gisbert, 2006. On pure syntax (uncontamined by information structure). In: Brandt, Patrick, Fuss, Erik (Eds.), Form, Structure and Grammar. Akademie Verlag, Berlin, pp. 137-157.

Fanselow, Gisbert, 2007. The restricted access of information structure to syntax. A minority report. In: Féry, Caroline, Fanselow, Gisbert, Krifka, Manfred (Eds.), The Notions of Information Structure, Working Papers of the SFB 632, Interdisciplinary Studies on Information Structure (ISIS) 6, $195-211$.

Féry, Caroline, 2006. The fallacy of invariant phonological correlates of Information Structural Notions. In: Féry, Caroline, Gisbert Fanselow, Manfred Krifka

(Eds.), The Notions of Information Structure, Working Papers of the SFB 632, Interdisciplinary Studies on Information Structure (ISIS) 6, $160-181$.

Givón, Talmy (Ed.), 1994a. Voice and Inversion. Benjamins, Amsterdam.

Givón, Talmy, 1994b. The pragmatics of de-transitive voice: functional and typological aspects of inversion. In: Givón (Ed.), pp. 3-44. 
Gundel, Jeanette K., Hedberg, Nancy, Zacharski, Ron, 1993. Cognitive status and the form of referring expressions in discourse. Language 69 (2), $274-307$. Haviland, Susan E., Clark, Herbert H., 1974. What is new? Acquiring new information as a process of comprehension. Journal of Verbal Learning and Verbal Behavior 13, 512-521.

Hellmuth, Sam, Skopeteas, Stavros, 2007. Information structure in linguistic theory and in speech production: validation of a cross-linguistic dataset. Interdisciplinary Studies on Information Structure (ISIS) 8, 141-186.

Jelinek, Eloise, 1990. Grammatical relations and coindexing in inverse systems. In: Dziwirek, Katarzyna, Patrick, Farrell, Mejías-Bikandi, Errapel (Eds.), Grammatical Relations: A Cross-Theoretical Perspective. The Stanford Linguistics Association, Stanford, pp. 227-246.

Jelinek, Eloise, Willie, MaryAnn, 1996. "Psych" verbs in Navajo. In: Jelinek, Eloise, Midgette, Sally, Rice, Keren, Saxon, Leslie (Eds.), Athabaskan Language Studies. University of New Mexico Press, Albuquerque, pp. 15-34.

Kiss, Katalin É., 1998. Identificational focus versus information focus. Language 74 (2), 245-273.

Klaiman, M.H., 1991. Grammatical Voice. Cambridge University Press, Cambridge.

Krifka, Manfred, 2007, Basic notions of information structure. In: Féry, Caroline Fanselow, Gisbert, Krifka, Manfred (Eds.), The Notions of Information Structure. ISIS 6, 13-55

Lambrecht, Knud, 1994. Information Structure and Sentence Form. Cambridge University Press, Cambridge.

Lambrecht, Knud, 2001. A framework for the analysis of cleft constructions. Linguistics 39 (3), 463-516.

Lehmann, Christian, Shin, Yong-Min, Verhoeven, Elisabeth, 2002. Person Prominence and Relation Prominence: On the Typology of Syntactic Relations with Particular Reference to Yucatec Maya. Lincom Europa, München.

Matić, Dejan, 2003. Topics, Presuppositions, and Theticity: An Empirical Study of Verb-Subject Clauses in Albanian, Greek, and Serbo-Croat. PhD Dissertation, University of Cologne.

Mühlbauer, Jeff, 2007. Word Order and the Interpretation of Nominals in Plains Cree. Ms., University of British Columbia.

Prince, Ellen F., 1981. Towards a taxonomy of given-new information. In: Cole, Peter (Ed.), Radical Pragmatics. Academic Press, New York.

Quesada, Diego J., 2000. A Grammar of Teribe. Lincom Europa, München.

Reinhart, Tanya, 1982. Pragmatics and linguistics: an analysis of sentence topics. Philosophica 27, 53-93.

Rizzi, Luigi, 1997. The fine structure of the left periphery. In: Haegeman, L. (Ed.), Elements of Grammar. Kluwer, Dordrecht, pp. $281-337$.

Shibatani, Masayoshi, 1985. Passives and related constructions. Language 61 (4), 821-848.

Silverstein, Michael, 1976. Hierarchy of features and ergativity. In: Dixon, R.M.W. (Ed.), Grammatical Categories in Australian Languages. Australian Institute of Aboriginal Studies, Canberra, pp. 112-171.

Skopeteas, Stavros, Fanselow, Gisbert, 2009a. Effects of givenness and constraints on free word order. In: Zimmerman, Malte, Féry, Caroline (Eds.), Information Structure from different perspectives. Oxford University Press, Oxford, pp. 307-331.

Skopeteas, Stavros, Fanselow, Gisbert, 2009b. Focus types and argument asymmetries: a cross-linguistic study in language production. In: Breul, Carsten (Ed.), Contrastive information structure. Benjamins, Amsterdam/Philadelphia.

Skopeteas, Stavros, Fiedler, Ines, Hellmuth, Sam, Schwarz, Anne, Stoel, Ruben, Fanselow, Gisbert, Féry, Caroline, Krifka, Manfred, 2006. Questionnaire on Information Structure (QUIS). Interdisciplinary Studies on Information Structure (ISIS), vol. 4. Universitätsverlag Potsdam, Potsdam.

Szendroi, Kriszta, 2001. Focus and Syntax Phonology Interface. PhD Dissertation, UCL.

Thompson, Chad, 1994. Passive and inverse constructions. In: Givón (Ed.), pp. 47-63.

Wedgwood, Daniel John, 2003. Predication and Information Structure: A Dynamic Account of Hungarian Pre-verbal Syntax. PhD Dissertation, Univ. of Edinburgh.

Whistler, Kenneth W., 1985. Focus, perspective, and inverse person marking in Nootkan. In: Nichols, Johanna, Woodbury, Anthony C. (Eds.), Grammar Inside and Outside the Clause: Some Approaches to Theory from the Field. Cambridge University Press, Cambridge, pp. $227-265$.

Zúñiga, Fernando, 2006. Deixis and Alignment: Inverse Systems in the Indigenous Languages of the Americas. Benjamins, Amsterdam.

\section{Glossary}

ANIM: animate

$C L$ : classifier

$D E F$ : definite

DIM: diminutive

HESIT: hesitation marker

$I N V$ : inverse

IPFV: imperfective

$O B V$ : obviative

PFV: perfective

$P L$ : plural

POSS: possessive

PERF: perfect

PROSP: prospective

PRS: present

$Q$ : question particle

$R E L$ : relativizer

SG: singular

SUBL: sublative

TOP: topic

J. Diego Quesada PhD in Linguistics (University of Bielefeld, Germany, 1994); Assistant Professor at the University of Toronto (Canada, 1995-2001). Grants: Socia Sciences and Humanities Research Council of Canada (1998-2000), which resulted in A Grammar of Teribe (2000, Munich: Lincom); Alexander-von-HumboldtFoundation (2002), led to the publication of The Chibchan Languages (2007, Cartago: Editorial Tecnológica). Quesada has worked as a Visiting Professor at the Federal University of Rio de Janeiro (Brazil) and at the Zulia State University (Venezuela), both in 2001. Since 2004 he is Professor of Linguistics at UNA.

Stavros Skopeteas received his PhD in General and Comparative Linguistics at the University of Erfurt and is currently working at the University of Potsdam (Linguistics Department, SFB 632 Information Structure). He has published a number of studies on language typology and language theory with main emphasis on the typology of spatial relations and information structure. 